\title{
Neuro-linguistic Programming and Its Implications for English Language Learners and Teachers
}

\author{
Neda Hedayat \\ Department of Language Teaching and Translation, Varamin-Pishva Branch, Islamic Azad University, Varamin, Iran \\ Reza Raissi \\ Department of Language Teaching and Translation, Varamin-Pishva Branch, Islamic Azad University, Varamin, Iran \\ Solmaz Azizzadeh Asl \\ Department of Language Teaching and Translation, Varamin-Pishva Branch, Islamic Azad University, Varamin, Iran
}

\begin{abstract}
In the world we live in, education is praised as a base for training and nurturing future generations and teaching is considered as a valuable profession through which future generations are flourished. The main components of each educational system must work well in order to create a successful system and achieve the desired results. Teachers are considered as one of the key determinant factors and active decision-makers of any educational system. Learners are also taken into account as one of the main elements of the system who are instructed to reach some educational goals. Neuro-linguistic programming (NLP), with high potential for English teaching and learning, is regarded as a supplementary technique which helps the teachers to develop outstanding skills like critical thinking, self-efficacy, and rapport which are necessary to bring on success and achievement to the education and to support learners to achieve excellence in their performance. The article first presents a brief history and definition of NLP. Then it is followed by some information about the main pillars of neuro-linguistic programming. The discussion then turns to understanding some of the implications of NLP for English language teachers and learners and its potential for educational success.
\end{abstract}

Index Terms—neuro-linguistic programming, learners' success, teachers' success

\section{INTRODUCTION}

Language is at the heart of human being life. We use it to show our feelings, to reach our desired outcomes, to pray, or to express our ideas. Through language, we exchange our attitudes and experiences, plan our lives and form individual and social identities. Some people are capable of doing things in more than one single language. Knowing more than one language may mean having a chance to get educated, get a job, having the opportunity to immigrate to other countries, expand the cultural horizons, and talk to other people with different linguistic and cultural backgrounds. So we can claim that language is the most unique feature of the creature. In today's globalized scenario, in which many people know more than one language, and with the technological developments which have made our world a global village, acquiring the ability to communicate effectively has become obligatory. Learning English as the language of international communication which enjoys the status of lingua franca has become necessary for anybody who wants to interact and communicate with other individuals around the world.

In the past decades, communicative competence and the interactive aspect of language were not emphasized by the methods and techniques used by language teachers. But nowadays, methods like communicative language teaching or CLT has become popular in most educational organizations. Neuro-linguistic programming has been recognized as a tool which can help the English language learners to improve the communicative competence, presentation skills and body language effectively (Siddiqui, 2018).

As teachers are considered as the key components of the educational system who affect its success, so identifying the elements which help them in teaching profession is very important. NLP is regarded as a supplementary technique which helps the teachers to develop outstanding skills necessary to bring on success to the education and to support learners to achieve excellence in their performance. It is also helpful for language teachers to establish a better communication with the learners, strengthen the educational environment, and have a supportive and effective interaction which leads to the higher academic achievement. The present article first presents a brief history and definition of neuro-linguistic programming and then it introduces the main pillars of NLP. In the next sections, some of the implications of NLP for English language teachers and learners are provided and discussed.

\section{NeURo-Linguistic Programming}

Neuro-Linguistic Programming (NLP) is an interpersonal communication system, developed by John Grinder, an associate professor of linguistics, and Richard Bandler, a mathematician and a graduate student of psychology, in the early 1970 s as a new method to language teaching. It is a collection of strategies, techniques, and patterns which are 
used for effective communication, growth, and personal change. The originators of NLP studied different patterns of beliefs and subjective experiences of the people with excellent behavior (Revell \& Norman, 1997) in order to discover the structures of excellence. As they believe that all behaviors have some certain structures, and by discovering the excellent patterns and modelling them, it is possible to repeat the same patterns and gain the same favorable results. Grinder and Bandler claim that neurological processes $(\mathrm{N})$, language (L), and behavioral patterns learned through experience $(\mathrm{P})$ are interconnected, and human beings can alter them and it is possible to change them to reach the desired goals in life. As a matter of fact, neuro-linguistic programming consists of certain techniques for communication and personal development. Generally speaking, it is based on some notions about the structure of the mind, the way it works, and the way individuals act and interact. Based on neuro-linguistic programming, human being should be taken into account as a whole mind-body interpersonal communication system with consistent, patterned connections between three main areas: Neuro (neurological processes), Linguistic (language), and Programming (behavioral strategies. 'Neuro' reflects the neurological processes (or how the body and mind interact). In other words, it relates to the way you use senses to understand things and happenings around. The second element which is 'Linguistics' is the matter of thought patterns and the language which is applied for interpersonal communication. In other words, NLP accounts for the neurological processes through which we experience and process information by our senses (auditory, visual, olfactory, kinesthetic, and gustatory). The other element, 'Programming', is the way we nurture the mind through interpreting the patterns of an individual's behavior and language use in order to reach the desired results. In other words, it is related to the ability to organize thoughts and ideas. The pragmatic approach of neurolinguistic programming uncovers important elements regarding the learners' mind and thought process by evaluating the kind of language used by them in order to change thoughts and actions and reach the educational goals.

Bandler (1985) claims that the experiences are sent, processed, and stored to the brain for which each person has a physical location. One of the main skills of NLP is recognizing the way people think, as there is a belief that each person has a preferred sense of taking in information that should be discovered in order to help learners maximize their learning (Alamdar \& Karbalaei, 2015). As NLP is taken into account the learning styles of students, so teachers should be aware of all linguistic, physical, cognitive, and behavioral structures of the students which are demonstrated in information processing and learning through the aforementioned senses. In this sense, as Miller (1981) declares, teachers should stay tuned within the same channel of communication (visual, auditory, or kinesthetic) in order to establish more effective communication with the learners.

Another aspect of NLP is the special focus on brilliance and quality. Neuro-linguistic programming studies brilliance and quality. In other words, it studies the way successful and outstanding individuals and organizations reach their ideal goals. According to Siddiqui (2018), teachers can apply different techniques of NLP in order to analyze the kind of language used by students and take into account the thought process of them. This knowledge helps them to become capable of changing thoughts and behaviors in a way that leads to desirable outcomes. According to the Bandler and Grinder's point of view, NLP is 'the psychology of excellence' or 'the art and the science of excellence'. They have started their studies based on the predisposition that some people do affairs in an excellent way while others don't. So they started to find out what makes 'outstanding performers' outstanding, as they believe that all the individuals can become outstanding performers just by doing the same directions, irrespective of their past or present (Lady, 2007). Joanne Walter and Ardeshir Bayat call it "a process that can be applied to model excellence in any field" (Walter, Bayat, 2003). As a matter of fact, the key driving force of NLP pioneers was discovering the mystery of excellence. The proponents of neuro-linguistic programming do claim that excellence is not a natural talent and it is learnable (Walter and Bayat, 2003). They also assert that excellence is not rare and anybody can be equipped with this crucial property. The only thing which is required is that individuals free themselves from any limitations and take into account various choices.

NLP is also considered as a supplementary tool applied in the field of second or foreign language instruction in order to assist learners to become excellent performers. There is a belief that by understanding the process of HOW and REPEATING the same process the same result will be acquired, otherwise, we can CHANGE the whole process or part of it in order to reach another different result. While altering the process is regarded as behavioral change, repeating the process of doing something is called modeling. The idea of modeling is applicable in any aspect of life including educational settings. Revell and Norman (1997) introduce 13 important rules which should be a part of the teachers' belief system and shape the instruction procedure:

1. Mind and body act as components of the same system which are interconnected and affect each other.

2. All human beings have special maps of the world and these maps are not the territory.

3. Failure doesn't exist, only feedback. There is no such thing as failure and there is always another chance to become successful.

4. When we do believe that something is true, the map becomes the territory. So it is either true or it becomes true.

5. You should know exactly what do you want. This view will help you to get it.

6. Any resource which is needed for our goals exists inside us.

7. Communication has verbal and also nonverbal forms and it is not just limited to one of them.

8. The unconscious mind is superior and kind.

9. Communication has conscious and nonconscious forms. 
10. All behaviors have a positive intention behind them.

11. The meaning of communication is manifested by the response we get.

12. We should model each excellent behavior in order to reach excellence.

13. Flexibility is a crucial element of any system.

\section{Pillars of Neuro-Linguistic Programming}

There are four key pillars or principles for NLP (O'Connor and McDermott 1996; Revell and Norman 1997):

1. Rapport: According to the Oxford dictionary, rapport is defined as "a close and harmonious relationship in which the people or groups concerned understand each other's feelings or ideas and communicate well." Webster (1984) describes rapport as a relationship marked by affinity, harmony, and accord. When the teacher and learners are in harmony or rapport, the teaching process becomes easier. As Delbio and Ilankumaran (2018) suggest, one of the main pillars of neuro-linguistic programming is creating effective communication and it is believed that rapport is very important in this regard, because it maximizes the similarities and minimizes the differences between individuals. It is believed that for developing rapport, teachers should develop behaviors similar to students which is possible through "mirroring". Rapport is an empathy that is shaped subconsciously between individuals. As asserted by Silva (2017), strategies of NLP are effective in creating rapport or empathy and can be applied to make a closer relationship between teacher and student. Consequently, teachers can use them to provide a more supportive and fruitful learning environment which results in higher productivity and success. As we live with communities and we are not alone so having the ability to generate rapport and effective communication is a must. In this regard, we should shape relationships with mutual trust and responsiveness.

2. Outcome thinking: This pillar relates to individuals' goals. It suggests that people should know what do they want and set their goals clearly for themselves, as precision is a key to success. It is asserted that the more individuals are aware of their wants and desires, the more likely they will reach them. In other words, NLP is based on a premise that precision helps individuals to achieve their goals. So, we should know exactly "what we want". There are five steps for this rule:

- Appreciate your goal as an important and attractive desire, and make it as compelling as possible.

- Focus on your desired goal all day long, and set your mind on a path ending to your objective. So, you will pass the way much easier.

- Imagine that your dream has become true and you have already achieved your goal. Your visualization is very important and you should draw a clear picture in your mind. Then, walk back and try out the path to your desired end.

- Concentrate on all the steps of the pathway. You should be aware of all resources, actions, and all the individuals who help you through the way and take all of them into account.

- With new insight, step back to the present and take action to reach the goal.

3. Sensory awareness: It is related to the idea that we use our senses to experience the world and to see, hear, or feel what is happening to us. When we use our senses, the feedback which is gained helps us to adjust our actions towards reaching the desired goals.

Sensory acuity or awareness means that by using senses, individuals become aware of the environment and things that happen around. Based on NLP, this knowledge is very important for our success. In many cases, individuals used to do things without considering what works and what does not. When people try to reach their objectives, they must also develop a level of awareness that enables them to distinguish between what is working (which helps them to reach the desired outcome) and what is not.

4. Behavioral flexibility: It is related to adaptability in the entire situation. It also means that when we have various choices of action, our chance of success increases. In order to reach different outcomes, we must change the way things are done. And according to NLP, we must keep changing the process until we get what we want. So flexibility in behavior is a key to success. The science of Cybernetics has got a rule claiming that "in any system, the part with the greatest range of freedom will be the one controlling the system." Generally, one of the important directions of neurolinguistic programming is encouraging people to increase their behavioral flexibility and to be more adaptable in different situations and accept the changes in life.

\section{IMPLICATIONS FOR THE LEARNERS}

Neuro-linguistic programming is believed to be an influential tool that affects the personal and educational life of the learners. It has the potential to improve the life quality, develop positive attitudes, provide support to resolve the psychological complications, help to make better decisions, establish effective communication, and foster language learning. As it is emphasized by García \& Tamayo (2017), language learners can use NLP as a psychotherapeutic technique to improve their performance and take a step towards achievement. One of the main implications of neurolinguistic programming is its assistance in the field of English language learning.

Moharamkhani, Karimi, and Ahmadi (2016) have investigated the effect of neuro-linguistic programming on vocabulary learning and after 12 sessions of treatment by swish pattern which is one of the NLP strategies, they have 
concluded that it has a significant effect of English language learners' vocabulary achievement. The researcher of this study point to the view that NLP is practical for all type of learners with different learning styles, consequently it can be a good choice for English classes. According to the originators of NLP, Bandler and Grinder (1985), swishing is a process by which the pattern of thought which leads to undesirable behavior is destroyed in order to be replaced by another favorable behavior. The originators claim that this process necessitates the visualizing a cue which is related to that undesirable behavior. The Swish pattern gives a new direction to the brain and the behavior goes after the same direction, so the new wanted behavior is shaped. In this study, the researcher has used swishing elements such as strategy introduction, practice, and feedback and followed these steps: context identification, cue identification, drawing the 'cue' picture, and finally, swishing and testing. As an example, when the teacher wants to teach the word 'habit' to the students, he or she asks students to imagine the hands of a smoker while smoking cigarettes and doing the bad habit. Then students are asked to repeat the words 'habit' and 'bad habit'. After this part, students are asked to imagine a healthy guy who looks fit and energetic and repeat the words 'habit' and 'good habit'. Then, learners should change their mental picture from a smoker to a healthy guy (swish pattern) and say the word 'habit' repeatedly. Students are asked to talk about some good and bad habits they have, and make different sentences with the word 'habit'. In this manner, learners have visualized a specific outcome of a certain situation which leads to a bad habit and should be avoided. The repetitions and visualizations are continued at home after each session and they are discussed in the next session. After examining the results of the posttest, the researcher concludes that the NLP strategy is satisfactory and it can be a very good strategy for vocabulary learning.

According to Alamdar and Karbalaei (2015), NLP is a useful tool for increasing the self-esteem of English language learners. In the study, they have selected four classes and used old methods of language teaching for the control group and NLP strategies and also old methods for the experimental group. The results of the study indicate that NLP is a beneficial tool to increase learners' self-esteem. As they explain, speaking is the most challenging skill among four skills of English learning and it needs a great deal of self-esteem and motivation. Neuro-linguistic programming provides some effective learning strategies and changes the limiting beliefs of the learners from "I cannot learn English" to "I can learn English". The researchers of this study have selected some stories to connect culture and language. Life lessons are used to build self-esteem and summary activities are also applied after reading or listening to the selected stories. Visualization is another strategy of NLP, as there is a belief that when learners know what exactly they want, they will achieve it. So they are required to write down their objectives and follow the motion pictures. They should also create some mental images through visualization for better retention and recall of information.

In a study carried out by Farahani (2018), the effect of neuro-linguistic programming on reading comprehension of English ESP students has been investigated. The researcher has selected two intact groups with 30 participants in each as an experimental and control group and has implemented NLP strategies for the reading skill of the experimental class. The results of the posttest which is drawn by ANCOVA clearly show that the implemented techniques have been successful for the intended purpose. Ten passages are taken from a reference book with the title "Reading Science and Medicine in English" as the materials of the study. In one session, all eight selected techniques of NLP are explained for the experimental group. The researcher has also clarified how to set objectives, what learning styles do exists, how to use senses in order to learn another language, and the effect of human emotions in language learning. After recognizing the specific learning style, the students are asked to read the passages using their own style. As an example, auditory learners read the passages aloud for themselves or listen to audio materials, or have some background music while reading the passage. Instead, kinesthetic learners have some hand movements or try to write the information. This category is allowed to walk for a while if it helps to feel better or try role-play activities related to the content of the text. By informing the learners of their own sensory learning styles and also teaching reading NLP techniques related to the specified styles, the researcher finally concluded that NLP strategies have a significant effect on ESP students' reading comprehension and this finding can be applied by English teachers in order to improve this essential skill of the learners.

Pourbahreini (2015) has investigated the effect of neuro-linguistic programming on grammatical knowledge of EFL students. In her study, passive sentences are concentrated and 60 students are selected to examine the research question. After administrating different tests and homogenizing the participants, the intervention program which is teaching through NLP activities is applied. Strategies of NLP which are used for this purpose are anchoring, VAK or visualauditory-kinesthetic, role-play, and so on. Visual learners are taught in an entertaining fashion, and they work on passive and active voices in pairs. The results show a great deal of difference between the pretest and posttest of the experimental group. Therefore, the researcher has concluded that NLP can be a useful strategy for teachers and learners who work on the grammatical accuracy of the English language.

\section{IMPLICATION FOR TEACHERS}

Education is one of the most important human activities and teachers are the most important influential elements in any educational system that helps learners to reach their objectives. Different studies over the last decades have confirmed that teachers have an essential effect on the students' academic and life-long success (e.g., Chetty, Friedman, \& Rockoff, 2014; Jackson, 2012; Nye, Konstantopoulos, \& Hedges, 2004). There are many elements that help teachers in their valuable profession and enable them to do their best and become effective and successful teachers. Despite the fact that education, experience, and certification are related to the effectiveness of teachers, there are many critical skills 
and classroom activities that matter most to students' achievement. Scholars believe that the main professional responsibility of teachers as educators is changing the behavior of students towards certain maturity and this process is possible with a series of activities for which teachers have a decisive role. It is believed that neuro-linguistic programming is a very useful tool for the language teaching profession which can be applied as a supplementary technique to improve the effectiveness of the teachers (Gewasari, Manullang, and Sibuea, 2017). It provides strategies for language teachers and learners to change their unproductive learning habits and experience successful and effective language learning.

According to Siddiqui (2018), anchoring, rapport building, metamodeling, and mirroring are some of the key elements of neuro-linguistic programming which can help language teachers in performing a better teaching atmosphere. The researcher defines anchoring as a technique of NLP which shapes a positive mental image or attitude towards learning with the assistance of anchors. In this way, special gestures, expressions, and body movements are created which are the results of positive emotions and confident state of mind. It has been proved that anchoring is a very effective technique for language learning.

Building rapport is also important for language learning (Delbio and Ilankumaran, 2018). As it is defined in the Oxford dictionary, rapport is "a close and harmonious relationship in which the people or groups concerned understand each other's feelings or ideas and communicate well." Proponents of NLP stress that English language teachers should do their best to establish rapport with their learners and thereby accelerate the learning process. In such a conductive environment, any gaps in communication will be filled and effective interactions will be shaped. In general, when a safe and supporting learning environment is created, the confidence of the learners is increased and they get ready to accomplish the assigned tasks and activities and they take a step towards their educational success (Comenius, 2009).

Mirroring is another NLP technique that is applied in order to create effective communication (Siddiqui, 2018). NLP practitioners claim that in order to establish rapport among language learners, gestures, postures, facial expressions, breathing patterns, etc. should be mirrored. Teachers can enhance verbal and non-verbal communication by using these patterns. Teachers should encourage learners to mirror behavioral patterns and language of fluent speakers in order to increase their motivation and promote their presentation and speaking skills. Mirroring and modeling are the key strategies of NLP which should be practiced to reach excellence. In this way, learners are assisted by the teachers to model the study patterns of successful performers in order to reach similar academic results. Therefore, as Siddiqui (2018) concludes, English language teachers can apply the strategies and techniques on neuro-linguistic programming to make the language learning process more attractive and interesting. NLP strategies help English language teachers to act as facilitators and enhance the interpersonal and communicative skills of the learners and improve their personality in a way that they can face the world with more confidence.

Neuro-linguistic programming is based on neurology and communication. It is based on the view that human beings have different learning styles and perceptual preferences which should be taken into account by language teachers. In the process of language learning, learners use their five senses which are called representational systems. They include auditory (for listening or hearing something), visual (for looking and seeing), olfactory (for smelling), gustatory (for tasting), and kinesthetic (to feel internally and externally). One of the responsibilities of ELT teachers is recognizing these features and deciding on optimal teaching solutions. Based on Pishgaman and Shayesteh (2014), when language teachers pay more attention to these differences and provide more effective external and internal learning atmosphere and apply sensory reach language, they assist language learners to learn in a more productive and easy way. More variety in teaching is also another consequence of NLP application in language instruction (Winch, 2005). It is believed that there is a lead system (neutral, auditory, visual, and kinesthetic) that should be recognized by the teachers and learners to improve language learning effectiveness. Practitioners claim that language teachers are able to affect the way materials are used by the learners but they cannot affect the way learners store them. What is clear is that learners who are aware of their lead system can use expressions in English consciously which are more in harmony with the way they process and store the input. In order to identify the preferred learning style, practitioners suggest some questionnaires which can be used by teachers and learners. According to Winch (2005), eye movement and learners' traits and behaviors (including their verbal and non-verbal communication) are the clues delivered unconsciously and should be taken into account in order to recognize the learners' tendencies. Eye movement is a sign which reveals the way a person processes information. Looking right, left, or up is a sign of visual processing while looking either side or down is the indicator of kinesthetic processing, and looking to either side means an auditory style of processing information (Hamilton 2005; Revell and Norman 1997). Certain traits or behaviors are also considered to distinguish different learners based on their lead system (Robbins, 1997). As an example, using phrases like "That's the way I see" is an indicator of a visual person. These people may talk with a high-pitched nasal voice and may have muscle tension in the upper part of the body especially abdomen and shoulders. The individuals with the auditory lead systems have a more balanced tone than visual ones. They take a more deep breath and even muscle tension is more balanced in this category. Speech tone in kinesthetic individuals is deep and slow. When they start to speak with someone, they have frequent pauses. Strong and solid posture is the other trait of this category. Teachers who are aware of these preferred representational systems which are different from one individual to the other can teach more effectively. Students who know their lead system are also capable of selecting suitable words and expressions. In general, the key to lesson 
planning is that teachers know exactly what do they want and what is their objective and combining it with the desires and wants of the learners (Winch, 2005).

Peker (2010) points to the strategies of thinking and reprogramming provided by neuro-linguistic programming which enable us to change our structures of thought and reprogram ourselves and accordingly reach our desired outcomes. There is a belief that our behaviors are accompanied by internal states and also some kind of internal thinking process. In order to change our behaviors, we should understand these internal states and thought structures. There are three ways of thinking: visual thinkers, auditory thinkers, and kinesthetic thinkers. NLP practitioners also believe that we should change ourselves to change the whole world. They claim that "We're not the victims of the world we see; we're the victims of the way we see the world". They point to reprogramming as behavioral patterns that are learned through different experiences and can be arranged in a way that leads to our desired objectives in life. We should reprogram our habits in order to change them, so language teachers should adopt different sets of principles to make personal development in personal or professional contexts and make substantial differences. To make these changes, there are some key points that should be taken into account by language teachers. We should avoid listening to negative people and improve the habit of positive thinking. We should also remember that words are very powerful and the positive language should be used all the time. Never listen to the people that give negative feedback to your potentials and always try to tell you that you can't achieve your dreams. When we break the prison and become free of negative thoughts, we will improve the inner world, and stay at peace and reach our desire outcomes and excellence (Peker, 2010).

Marashi and Abedi (2017) have investigated the effect of neuro-linguistic programming on teachers' reflective teaching. They have selected 30 Iranian female English teachers for this study and after 20 sessions of treatment, they have tested the null hypothesis and have concluded that NLP affects English teachers' reflective teaching significantly. For this study, the researchers have introduced 8 NLP techniques to the English teachers: leading, rapport-building, elicitation, modelling, anchoring, individual differences, flexibility, and cognitive-emotional boosters. The participants of the study are required to think about their classes and write down on a paper whether they have applied these techniques subconsciously and whether they are familiar with them or not. They start talking about their related experiences in groups of three and discuss whether their procedures have been successful and how do they feel about them. After discussion, they watch some audio or visual materials regarding NLP strategies which are applied around the world. Again they have discussion and it is continued until they find that NLP strategies are helpful for effective English teaching. The second questionnaire which is used as a posttest shows positive effect of the treatment.

\section{CONCLUSION}

From the beginning of 1970s, English language teaching has changed from grammar translation and audio-lingual methods to the ones in which social and cultural backgrounds are taken into account and the priority has been given to the communicative competence. Traditionally, teachers were concentrating on providing the learners with grammar, reading, and repetition drills and enabling them to read and write in the target language without any errors. So in that time, oral communication in the target language was not concentrated by language teachers. But after technological developments and the necessity to have effective communication with other people around the world, the need for improving communicative competence instead of merely developing the linguistic competence was exposed to discussion. Teachers realized that students can't use expressions, gestures, and social language in their communications and the ability of communicating pragmatic language was greatly missing.

NLP is regarded as one of the recent scientific developments that connect mathematics to neurology and language. It deals with neurological and psychological factors and one of its main objectives is establishing effective communication. As different scholars suggest, neuro-linguistic programming has great potential to be used in the field of education. In fact, NLP is not a special method of language teaching and it is not comprised of various language teaching techniques. Instead, it is considered as a humanistic philosophy that includes a set of notions used to inform individuals about their preferred learning styles and convince them that they are powerful and strong enough to take the control of their affairs and reach excellence. As it is suggested by Pourbahreini (2015), the effect of neuro-linguistic programming on second language learning and teaching, especially English, has not been studied adequately. Still, the results of the conducted studies clearly show that NLP can make a great difference in education, specifically in the field of second language learning (Lankton, 1979). So English language teachers and learners can apply NLP principles and strategies to become more effective and successful and reach their educational outcomes.

\section{REFERENCES}

[1] Alamdar, F. S., \& Karbalaei, A. (2015). The Relationship between Neuro-Linguistic Programming and Anxiety and SelfEsteem among Iranian Intermediate EFL Learners. International Journal of Educational Investigations, 2(8), 108-130.

[2] Calaguas, G. M. (2013). Teacher effectiveness scale in higher education: Development and psychometric properties. International Journal of Research Studies in Education, 2(2), 3-20.

[3] Canrinus, E. T., Helms-Lorenz, M., Beijaard, D., Buitink, J., \& Hofman, A. (2012). Self-efficacy, job satisfaction, motivation and commitment: Exploring the relationships between indicators of teachers' professional identity. European journal of psychology of education, 27(1), 115-132. 
[4] Delbio, A., \& Ilankumaran, M. (2018). Second Language Acquisition through Neurolinguistic Programming: A Psychoanalytic Approach. International Journal of Engineering \& Technology, 7(4.36), 624-629.

[5] García, J. C. N., \& Tamayo, M. A. (2017). A Useful Chart for Providing Self-Assessment Opportunities to Students. International Journal of English Language Teaching, 4(2), 11-19.

[6] Harris, T. (2001). NLP if it works use it. CAUCE, Revista de Filología y su Didáctica, 24, 29-38.

[7] Kong, E., \& Farrell, M. (2012). Facilitating knowledge and learning capabilities through neuro-linguistic programming. International Journal of Learning, 18(3), 253-265.

[8] Lashkarian, A., \& Sayadian, S. (2015). The effect of Neuro Linguistic Programming (NLP) techniques on young Iranian EFL Learners' motivation, learning improvement, and on teacher's success. Procedia-Social and Behavioral Sciences, 199, $510-516$.

[9] Marashi, H., \& Abedi, M. (2017). The Impact of Neurolinguistic Programming on EFL Teachers' reflective Teaching. English Language Teaching, 7(3), 22-28.

[10] Moharamkhani, A., Karimi, L., \& Ahmadi, D. (2016). The Impact of Neuro Linguistic Programming (NLP) on EFL Learners' Vocabulary Achievement. Journal of Humanities and Social Science (IOSR-JHSS), 2(1), 15-36.

[11] Naim, M. (2017). Soft Skill Development: Relevance of Neuro-Linguistic Programming (NLP). Language in India, 17(2), 160176.

[12] Peker, B. G. (2010). Getting To Know The Art Of Excellence: What Neuro Linguistic Programming Can Offer To Teachers' Thinking And Reprogramming Skills. Ekev Academic Review, 14(44), 87-98.

[13] Pishghadam, R., \& Shayesteh, S. (2014). Neuro-linguistic Programming (NLP) for Language Teachers: Revalidation of an NLP Scale. Theory \& Practice in Language Studies, 4(10), 2096-2104.

[14] Pourbahreini, F. (2015). The Effect of Neuro-Linguistic Programming Technique on Enhancing Grammatical Knowledge of Iranian EFL Learners at Intermediate Level. English for Specific Purposes World, ISSN, 1682-3257, 44(16), 1-17.

[15] Ramganesh, E., \& Paulraj, I. J. M. (2015). Prospective Teacher Educators' Awareness towards the Key Components of NLP. International Journal of Academic Research in Management (IJARM), 4(1), 24-34.

[16] Rustan, E. (2017). Learning Creative Writing Model Based on Neurolinguistic Programming. International Journal of Language Education and Culture Review, 3(2), 13-29.

[17] Seitova, S. M., Kozhasheva, G. O., Gavrilova, Y. N., Tasbolatova, R., Okpebaeva, G. S., Kydyrbaeva, G. T., \& Abdykarimova, A. Z. (2016). Peculiarities of Using Neuro-Linguistic Programming Techniques in Teaching. International Electronic Journal of Mathematics Education, 11(5), 1135-1149.

[18] Shahmoradi, N., Nosratinia, M., \& Shangarffam, N. (2018). The Relationship among EFL Teachers' Critical Thinking, NeuroLinguistic Programming, and Their Sense of Efficacy. Journal of Applied Linguistics and Language Research, 5(2), 41-56.

[19] Sheybani, M., \& Miri, F. (2019). The relationship between EFL teachers' professional identity and their critical thinking: A structural equation modeling approach. Cogent Psychology, 6(1), 1-11.

[20] Siddiqui, Z. E. B. A. (2018). English language teaching through nlp: Techniques and methods. Research Journal of English Language and Literature, 6(2), 181-184.

[21] Skinner, H., \& Croft, R. (2009). Neuro-linguistic programming techniques to improve the self-efficacy of undergraduate dissertation students. Journal of Applied Research in Higher Education, 1(1), 30-38.

[22] Tarnopolsky, O. B. (2016). NLP, suggestology and stage-acting in teaching English as a second/foreign language. Innovative Solutions in Modern Science, 1(1), 1-11.

[23] Tosey, P., Mathison, J., \& Michelli, D. (2005). Mapping transformative learning: The potential of neuro-linguistic programming. Journal of Transformative Education, 3(2), 140-167.

[24] Tuzlukova, V., Al Busaidi, S., \& Burns, S. L. (2017). Critical thinking in the Language Classroom: Teacher Beliefs and Methods. Pertanika Journal of Social Sciences \& Humanities, 25(2), 615-633.

[25] Vieira, C. R., \& Gaspar, M. F. (2013). PLENATITUDE Teacher Education for Effectiveness and Well-Being with NeuroLinguistic Programming. Online Submission, 3(1), 1-17.

[26] Winch, S. (2005). From frustration to satisfaction: using NLP to improve self-expression. In EA Education Conference (Vol. 18). English Australia.

Neda Hedayat is an assistant professor in linguistics at Islamic Azad University, Varamin-Pishva branch. She has published several papers in national and international journals and presented several conference papers regarding TEFL issues, linguistics, and translation. Her main interest is applied linguistics, psycholinguistics, and quantitative and qualitative research. Currently, she is teaching several courses to BA, MA, and Ph.D. students at the English Department of Islamic Azad University, Varamin-Pishva branch. She has supervised several Ph.D. dissertations and Master theses.

Reza Raissi is an assistant professor in TEFL at the Islamic Azad University of Varamin-Pishva branch. He received his Ph.D. in TESL from UTM University, Malaysia. His main area of interest is teaching methodology, testing, and applied linguistics. Currently, he is teaching TEFL related courses for BA, MA, and Ph.D. students in several Iranian Universities.

Solmaz Azizzadeh Asl is a Ph.D. candidate in TEFL at the Department of Language Teaching and Translation Studies at Islamic Azad University, Varamin-Pishva branch, Iran. She has been teaching English at language institutions of Tehran and Sari for more than five years. She also translates English books and texts for different organizations. Her current research interests include extensive reading and neurolinguistics programming, and identity. 